\title{
Cross-industry M\&A and Industrial Restructuring in China: A Study Based on Social Network Analysis
}

\author{
Mei QUAN ${ }^{1, a,{ }^{*}}$ and Qi YUE ${ }^{2, b}$ \\ ${ }^{1}$ School of Economics and Management, South China Normal University, Guangzhou 510006, China \\ ${ }^{2}$ School of Economics and Management, South China Normal University, Guangzhou 510006, China \\ aquanmei1030@126.com, byueqi@m.scnu.edu.cn \\ ${ }^{*}$ Corresponding author
}

\begin{abstract}
Keywords: Cross-industry Mergers and Acquisitions (MIMAs), Industrial restructuring, Social network analysis.
\end{abstract}

\begin{abstract}
Cross-industry M\&A based on capital market plays an important role in industrial restructuring. Based on the cross-industry M\&A transaction data of Chinese listed companies from 1998 to 2013, this paper uses Social Network Analysis method to analyze the law of industrial transfer and restructuring indicated by cross-industry M\&A from the perspectives of network density, centrality, multidimensional analysis, and core-periphery structure analysis. The results show that the low density of cross-industry M\&A networks presents a small-world effect; the centrality of industries varies largely. Manufacturing, as the pillar industry in China, has the highest degree of centrality and is the center of China's industrial transfer and restructuring; cross-industry M\&A network shows an obvious Core-Periphery structure feature.
\end{abstract}

\section{Introduction}

Mergers and Acquisitions is an effective means for the expansion and development of enterprises, and an important way to optimize the resources allocation and upgrade the industrial structure. With the rapid growth of China' economy, Chinese companies' M\&A activities have become increasingly active and the industries involved have become wider and wider. At the present stage, many industries in our country face severe challenges, such as excess aggregates, dispersed capabilities, and excessive competition. Through M\&A to achieve industrial restructuring is bound to become an important choice for Chinese enterprises.

Industrial Ecology thinks that economic activities are complicated and there are many recycling paths, but they can ultimately be attributed to the flow of resources between departments. Cross-industry M\&A is the resources flow between industries, using Social Network Analysis (SNA) can clearly represent this complex resource flow path. SNA is a quantitative analysis method developed by sociologists based on mathematical, graph theory, etc. It is a mature method of analysis in sociology. Tichy(1979) claimed that significant advances can be made in organization theory and research by use the approach of Social Network Analysis. In the past decade, many scholars have introduced SNA into the study of economics and organizational management, it has been widely used in the studies of international multilateral negotiations (Money et.al,2008), international trade (Ma Shu-zhong et.al,2016; Liu Jin-song et.al,2016), staff exchange network (Kleinbaum et.al,2014), corporate transaction networks (Hou rui et.al,2010; Wei lei et.al,2012), city clusters (Fang Da-chun et.al,2015), entrepreneur social capital (You Jia-xing et.al,2014), Chain Board (Wan Liang-yong et.al,2014; Liang wen et.al,2018) and so on. Only Hou rui and Wei le used Social Network Analysis to study the cross-border merger and acquisition. However, cross-industry merger and acquisition is also a non-negligible approach for industrial transfer and reorganization. In a certain period of time, all cross-industry M\&A will form a complex relationship, which can be reflected by Social Network Analysis. This paper uses the M\&A data of Chinese enterprises from 1998-2013. Through the analysis of network index, the basic characteristics of cross-industry M\&A in China are obtained, and the industry resource transfer and restructuring behind the cross-industry 
M\&A network are explored. The research conclusion is conducive to the cross-industry M\&A decision making and macro industrial policy formulation.

\section{Data and Network Model}

This paper selects 3291 M\&A transactions initiated by Chinese listed companies in 1998-2013, excluding the terminated or failed M\&A transactions, the same industry M\&A transactions and missed transaction records. Eventually, 912 mergers and acquisitions events were taken as research objects.

Make 19 industries classified by the Securities and Futures Commission as nodes of the network, These 19 industries are: Agriculture, forestry, animal husbandry, fishery (A), Mining (B), Manufacturing (C), Electricity, heat, gas, and water production and supply (D), Construction (E), Wholesale and retail (F), Transportation, warehousing and post $(\mathrm{G})$, Accommodation and catering $(\mathrm{H})$, Information transmission, software and information technology services (I), Financial services (J), Real estate (K), Leasing and business services (L), Scientific research and technology services (M), Water conservancy, environment and public facilities management $(\mathrm{N})$, Resident services, repair and other services $(\mathrm{O})$, Education $(\mathrm{P})$, Health and social work (Q), Culture, sports and entertainment (R), General industry(S). M\&A between different industries as the edges of the network, then builds a cross-industry M\&A network. However, this network only considers whether the cross-industry M\&A relationship exists or not, ignoring two key factors (M\&A frequency and M\&A transaction amount). Therefore, taking these two factors into account and weighting the edges of the network, a weighted complex network of cross-industry M\&A is obtained. Just as shown in figure 1 and figure 2 . The data processing and visualization of network are completed by Ucinet software.

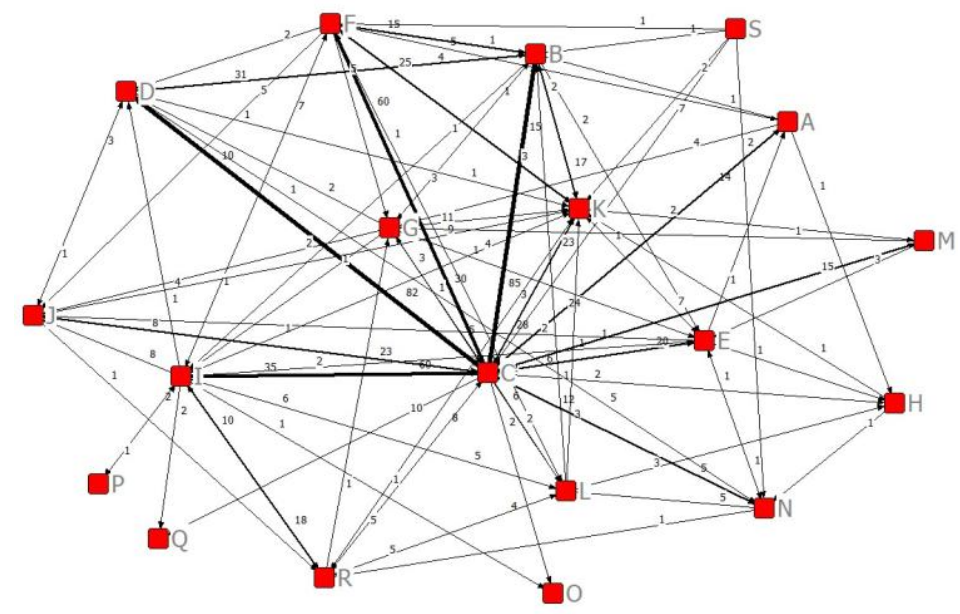

Fig.1 The network diagram of cross-industry M\&A Based on M\&A frequency

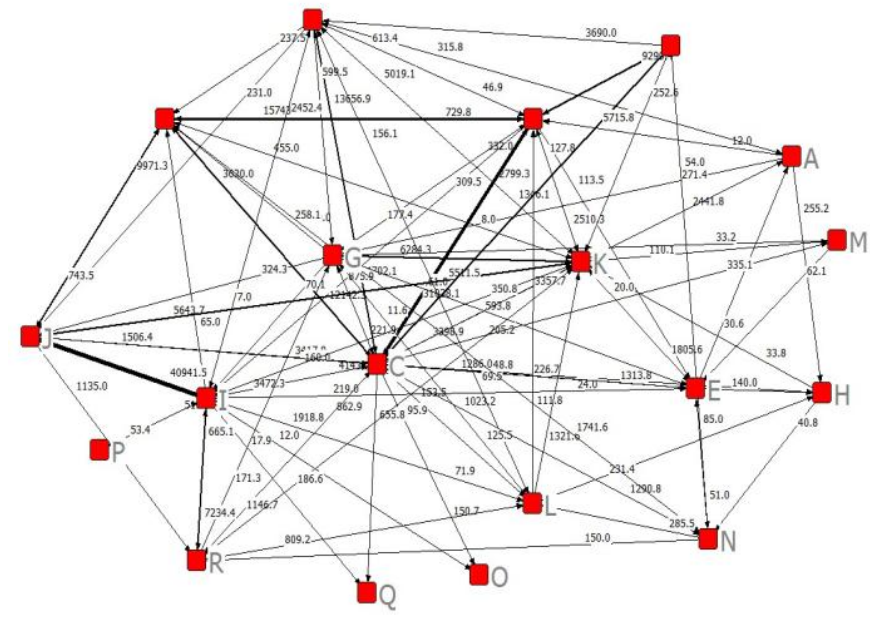

Fig.2 The network diagram of cross-industry M\&A Based on M\&A transaction amount (Unit: million) 


\section{Research Results}

\section{Network Density and "Small-world Network"}

The network density refers to the tightness between various nodes of the network. It can be obtained by comparing the number of actually existing relationships in the network with the theoretically possible relationships. The more connections between nodes, the greater the density. Density can measure the level of cohesion of an overall network, and its range is [0,1]. The cross-industry M\&A network density value is calculated to be 0.3158 , which indicates that the degree of tightness of cross-industry M\&A networks is not very high.

Travers and Milgram (1996) obtained a well-known conclusion from a small group's experiment that "anyone in the world can establish contact through about 6 steps". Therefore, the entire world is a small world. Small cosmopolitanism can be measured by two kinds of statistics, they are Characteristic path length (L) and Clustering coefficient (C). After calculation, the Clustering coefficient (C) of the cross-industry M\&A network is 0.515 , and the Characteristic path length $(\mathrm{L})$ is 1.686 . According to the concept of the small world, the cross-industry M\&A network constructed in this paper can show obvious small-world features.

\section{Centrality Analysis}

Centrality is an important indicator to measure the degree of centralization of the whole network. In cross-industry M\&A networks, industries in the network center are more likely to obtain information and resources, they have more resources, greater power, and stronger influence on other industries. According to the different calculation methods, centrality can be divided into degree centrality, betweenness centrality, closeness centrality and so on.

Degree Centrality. Degree centrality is the number of edges of a node, which reflects the number of M\&A between industries. If an industry is directly connected to many other industries, then its degree centrality is high and it is at the center of the whole network. Because of the directionality, degree centrality can be divided into out-degree and in-degree, and the out-degree and in-degree weighted by M\&A frequency and M\&A amount are also calculated.

Table 1 Degree centrality value of Cross-industry M\&A

\begin{tabular}{|c|c|c|c|c|c|c|}
\hline Rank & Out-Degree & In-Degree & $\begin{array}{c}\text { Out-Degree } \\
\text { (M\&A frequency) }\end{array}$ & $\begin{array}{c}\text { In-Degree } \\
\text { (M\&A frequency) }\end{array}$ & $\begin{array}{l}\text { Out-Degree } \\
\text { (M\&A amount) } \\
\text { Unit: million }\end{array}$ & $\begin{array}{c}\text { In-Degree } \\
\text { (M\&A amount) } \\
\text { Unit: million }\end{array}$ \\
\hline 1 & $\mathrm{C}(16)$ & $\mathrm{C}(13)$ & $\mathrm{C}(384)$ & $\mathrm{C}(220)$ & $\mathrm{C}(63810.637)$ & $\mathrm{J}(60624.031)$ \\
\hline 2 & $\mathrm{I}(11)$ & $\mathrm{K}(12)$ & $F(125)$ & $\mathrm{B}(154)$ & $\mathrm{I}(47529.625)$ & B(59496.398) \\
\hline 3 & $\mathrm{~K}(9)$ & $\mathrm{I}(9)$ & $\mathrm{I}(69)$ & $\mathrm{I}(98)$ & $\mathrm{D}(30339.398)$ & $\mathrm{C}(41532.270)$ \\
\hline 4 & $\mathrm{~F}(9)$ & $\mathrm{B}(8)$ & $\mathrm{K}(63)$ & $\mathrm{D}(98)$ & $\mathrm{F}(23281.549)$ & $\mathrm{K}(24689.059)$ \\
\hline 5 & $\mathrm{G}(8)$ & $\mathrm{D}(8)$ & $\mathrm{D}(46)$ & $\mathrm{K}(86)$ & $S(19002.811)$ & $\mathrm{D}(15925.870)$ \\
\hline 6 & $\mathrm{E}(7)$ & $\mathrm{J}(7)$ & $\mathrm{E}(33)$ & $\mathrm{J}(52)$ & $\mathrm{K}(13419.726)$ & I(14709.813) \\
\hline 7 & $\mathrm{~L}(7)$ & $\mathrm{E}(7)$ & $\mathrm{R}(30)$ & $\mathrm{F}(38)$ & $\mathrm{R}(9548.089)$ & $\mathrm{F}(9861.676)$ \\
\hline 8 & $\mathrm{~B}(7)$ & $\mathrm{G}(7)$ & $\mathrm{B}(26)$ & $\mathrm{A}(30)$ & $\mathrm{J}(9028.521)$ & $\mathrm{L}(3334.660)$ \\
\hline 9 & $\mathrm{D}(5)$ & $\mathrm{L}(6)$ & $\mathrm{G}(24)$ & $\mathrm{R}(27)$ & $\mathrm{G}(8062.619)$ & $\mathrm{R}(3168.927)$ \\
\hline 10 & $\mathrm{~N}(5)$ & $F(6)$ & $\mathrm{L}(20)$ & $\mathrm{L}(24)$ & $\mathrm{B}(4458.729)$ & $\mathrm{E}(1812.570)$ \\
\hline 11 & $S(5)$ & $\mathrm{R}(6)$ & $\mathrm{A}(20)$ & $\mathrm{G}(19)$ & $\mathrm{E}(3625.700)$ & $\mathrm{G}(1754.740)$ \\
\hline 12 & $\mathrm{R}(5)$ & $\mathrm{N}(5)$ & $\mathrm{M}(19)$ & $\mathrm{N}(17)$ & $\mathrm{N}(3518.940)$ & $\mathrm{N}(1752.990)$ \\
\hline 13 & $\mathrm{~J}(4)$ & $\mathrm{H}(4)$ & $\mathrm{N}(17)$ & $\mathrm{E}(16)$ & $\mathrm{A}(2980.367)$ & $\mathrm{A}(940.210)$ \\
\hline 14 & A(4) & $\mathrm{A}(3)$ & $\mathrm{J}(14)$ & $\mathrm{Q}(12)$ & $\mathrm{L}(2082.340)$ & $\mathrm{H}(675.400)$ \\
\hline 15 & $\mathrm{M}(3)$ & $\mathrm{M}(2)$ & $S(13)$ & $\mathrm{H}(7)$ & $\mathrm{M}(430.390)$ & $\mathrm{Q}(673.730)$ \\
\hline 16 & $\mathrm{H}(2)$ & $\mathrm{Q}(2)$ & $\mathrm{H}(2)$ & $\mathrm{M}(3)$ & $\mathrm{H}(74.630)$ & $\mathrm{M}(136.285)$ \\
\hline 17 & $\mathrm{P}(1)$ & $\mathrm{O}(2)$ & $\mathrm{P}(1)$ & $\mathrm{O}(3)$ & $\mathrm{P}(53.424)$ & $\mathrm{O}(107.860)$ \\
\hline 18 & $\mathrm{Q}(0)$ & $\mathrm{P}(1)$ & $\mathrm{Q}(0)$ & $\mathrm{P}(2)$ & $\mathrm{Q}(0)$ & $\mathrm{P}(51.000)$ \\
\hline 19 & $\mathrm{O}(0)$ & $S(0)$ & $\mathrm{O}(0)$ & $S(0)$ & $\mathrm{O}(0)$ & $S(0)$ \\
\hline Mean & 5.68 & 5.68 & 47.684 & 47.684 & 12697.236 & 12697.236 \\
\hline
\end{tabular}

From the analysis in Table 1, it can be seen that different industries show different in-degrees and out-degrees, and there are great differences. From the perspective of the horizontal comparison of various industries, manufacturing; information transmission, software and information technology service (We call it IT in the following) and the real estate are higher in degree centrality compared with other 
industries. It can be seen that these industries are in an important position in China, they are more active in cross-industry M\&A, and they show a clear tendency towards diversification. By calculating the correlation between the out-degree and in-degree of each node, the Pearson correlation coefficient is 0.824 , which is significantly correlated at the $1 \%$ level. Therefore, the implementation of M\&A in other industries and acceptance of M\&A in other industries has a significant positive relationship.

According to the analysis of the differences between M\&A frequency and M\&A amount, 19 industries can be divided into 3 types. (1) The acquirer industries. Companies in this type of industry are more often involved in the active acquisition of other industries. Such industries include manufacturing; IT; wholesale and retail trades, etc. (2) The acquired industry. Enterprises in this type of industry are more frequently acquired by other industries, such industries including real estate; finance and mining, etc. (3) Balanced industries. The frequency and amount of these industries in acquire events and acquired events are almost the same. From the table1, it can be seen that such industries mainly include construction; water conservancy and public facilities management; education; culture, sports and entertainment; transportation, warehousing and postal services; leasing and business services, etc.

Betweenness Centrality and Closeness Centrality. The betweenness centrality describes how much a node is in the shortest path to other industry pairs, that is, to what degree it controls the flow of resources, which measures the extent of the role of the node as an "intermediary". Closeness centrality measures an indicator that an actor is independent of other actor controls.

Table 2 Betweenness centrality value and Closeness centrality value of Cross-industry M\&A

\begin{tabular}{cccc}
\hline Rank & Betweenness & Out-Closeness & In-Closeness \\
\hline 1 & $\mathrm{C}(69.576)$ & $\mathrm{C}(16.50)$ & $\mathrm{C}(14.50)$ \\
2 & $\mathrm{I}(44.376)$ & $\mathrm{I}(14.00)$ & $\mathrm{K}(14.00)$ \\
3 & $\mathrm{~K}(26.535)$ & $\mathrm{K}(13.00)$ & $\mathrm{I}(12.50)$ \\
4 & $\mathrm{E}(10.743)$ & $\mathrm{F}(13.00)$ & $\mathrm{D}(12.00)$ \\
5 & $\mathrm{G}(7.876)$ & $\mathrm{G}(12.50)$ & $\mathrm{B}(11.83)$ \\
6 & $\mathrm{~N}(7.292)$ & $\mathrm{B}(12.00)$ & $\mathrm{J}(11.50)$ \\
7 & $\mathrm{~F}(7.218)$ & $\mathrm{E}(12.00)$ & $\mathrm{E}(11.50)$ \\
8 & $\mathrm{~B}(6.458)$ & $\mathrm{L}(12.00)$ & $\mathrm{F}(11.16)$ \\
9 & $\mathrm{~L}(6.158)$ & $\mathrm{S}(11.33)$ & $\mathrm{L}(11.00)$ \\
10 & $\mathrm{D}(4.410)$ & $\mathrm{R}(11.00)$ & $\mathrm{R}(11.00)$ \\
11 & $\mathrm{R}(4.067)$ & $\mathrm{D}(10.83)$ & $\mathrm{N}(10.33)$ \\
12 & $\mathrm{H}(1.750)$ & $\mathrm{N}(10.83)$ & $\mathrm{Q}(9.83)$ \\
13 & $\mathrm{~A}(1.167)$ & $\mathrm{J}(10.33)$ & $\mathrm{O}(9.33)$ \\
14 & $\mathrm{~J}(1.050)$ & $\mathrm{A}(10.33)$ & $\mathrm{A}(9.16)$ \\
15 & $\mathrm{M}(0.325)$ & $\mathrm{H}(8.83)$ & $\mathrm{M}(8.83)$ \\
16 & $\mathrm{O}(0)$ & $\mathrm{P}(8.00)$ & $\mathrm{P}(7.33)$ \\
17 & $\mathrm{Q}(0)$ & $\mathrm{O}(0)$ & $\mathrm{S}(0)$ \\
18 & $\mathrm{P}(0)$ & $\mathrm{Q}(0)$ & 10.325 \\
\hline
\end{tabular}

Table 2 shows the calculation results of the betweenness centrality and closeness centrality. It can be seen that the highest betweenness centrality is manufacturing, followed by IT and the real estate, indicating that companies in these industries have more resources and are responsible for the mediating role. Industries in manufacturing, IT and real estate have a high degree of closeness centrality indicating that these industries can reach other industries in the shortest distance, and they are at a comparatively central position in M\&A networks during the transaction process. The betweenness centrality and closeness centrality of the three industries in resident service, repair and other service industries; health and social work and education are ranked lower, indicating that these industries are relatively marginal in cross-industry M\&A networks.

\section{Multidimensional Scaling Analysis}

Through the multidimensional scaling analysis, the intricate cross-industry M\&A relationship can be displayed in a two-dimensional graph, and the relative position formed by M\&A relations among these industries can be more intuitively observed. The greater the M\&A frequency between two industries is, the greater the M\&A transaction amount is, the closer the two industries will be in the two-dimensional 
graph, and vice versa.

Figure 3 and Figure 4 are 2-dimensional scale analysis charts based on M\&A frequency and M\&A amount. From the figures, it can be seen that industries such as manufacturing, IT are in the center position, other industries are scattered on the edge of the map. By observing the relative distance between industries, the closeness of M\&A activity in various industries can be judged.

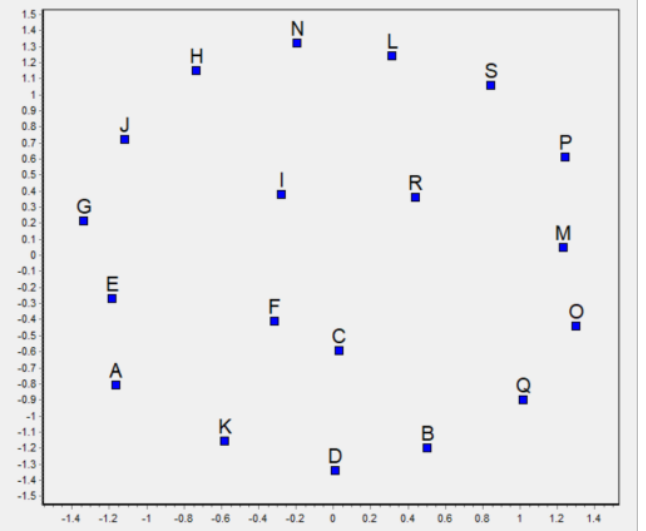

Fig. 3 The MDS Diagram of Cross-industry $M \& A(B a s e d$ on M\&A frequency)

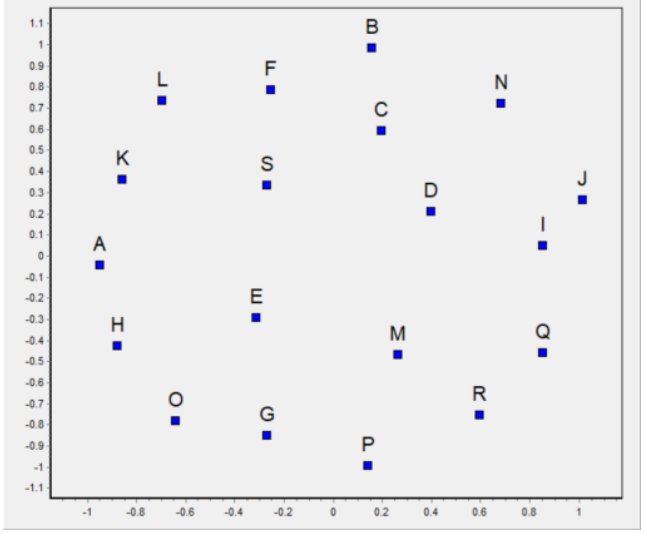

Fig. 4 The MDS Diagram of Cross-industry $\mathrm{M} \& \mathrm{~A}($ Based on $\mathrm{M} \& \mathrm{~A}$ transaction amount)

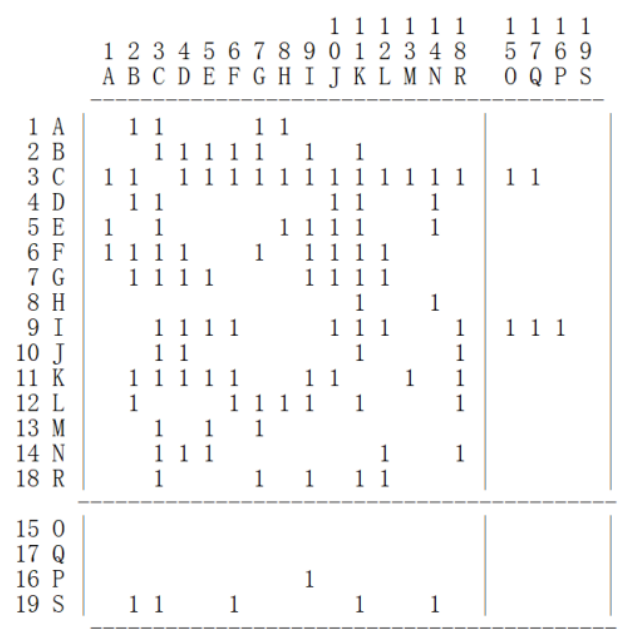

Fig.5 The Core/Periphery analysis results of cross-industry M\&A

\section{Core/Periphery Analysis}

The Core-Periphery analysis distinguishes between a higher density of actors (core) and a lower density of actors (periphery) based on how close the actors are to each other. In cross-industry M\&A networks, industries at the core position occupy an important position in the network.

After the calculation, the results are show as Figure 5, it can be seen that the four industries include resident services, repairs and other service industries; health and social work; education and general industry are at the periphery while the other 15 industries are at the core. Among them, the density of core industries is 0.462 , and the density of periphery industries is 0 . The industry clusters at the core position are closely related to M\&A, while the industries at the periphery are less in contact with each other.

\section{Conclusion and Suggestion}

The implementation of cross-industry M\&A by Chinese companies through capital markets is the result of diversified operations and rapid economic development in China. The main conclusions obtained through the analysis of the cross-industry M\&A network of Chinese listed companies a from 1998 to 2013 are as follow: 
Overall, the density of cross-industry M\&A networks is not very high. M\&A network has a small cosmopolitan nature, and it only needs to pass 1.686 industries that can connect any two industries in the network. Manufacturing has the highest degree of centrality and is the center of China's industrial transfer and restructuring. There is a significant positive correlation between the out-degree and in-degree of the industries. Based on the differences of M\&A frequency and M\&A amount, 19 industries can be classified into three types: the acquirer industries, the acquired industry, and balanced industries. The highest betweenness and closeness centrality are the manufacturing, followed by IT, and the real estate industry. These indicate that companies in these industries have more resources, playing an important intermediary role and are in a relatively central position in the cross-industry M\&A network. Multidimensional scale analysis also shows this distribution. The core-periphery structure analysis shows that 15 industries in 19 industries are relatively central, and other four industries of resident services, repair and other service industries; health and social work; education and general industry are marginal.

Based on the above analytic results, the following suggestions are made:

First, continue to promote cross-industry M\&A, implement open M\&A policies, improve the administrative approval of $M \& A$, encourage $M \& A$ based on industrial integration, promote industrial upgrading in traditional industries, and promote optimal resources allocation among industries. Second, strengthen the communication between the core industries and other periphery industries to promote the development of periphery industries. Third, manufacturing with the highest betweenness centrality should be encouraged to implement M\&A with other industries to eliminate low-efficiency companies and achieve vertical integration and diversified development of the industry chain.

\section{Acknowledgement}

This research was financially supported by the key projects of Philosophy and Social Sciences Research of Ministry of Education with project number 17JZD020 and 15JZD020, Guangzhou Philosophy and Social Science with project number 2017GZYB43 and the innovation project of graduate school of South China Normal University.

\section{References}

[1] W. Zhang, Thoughts on the industrial reorganization of China, Management World. 2 (2000) 58-63.

[2] A.M. Kleinbaum, T.E. Stuart, Inside the black box of the corporate staff: Social networks and the implementation of corporate strategy, Strategic Management Journal. 35, 1 (2014) 24-47.

[3] R. Bruce Money. International multilateral negotiations and social networks, J. Journal of International Business. 29, 4 (1998) 695-710.

[4] N.M. Tichy, M.L. Tushman, C. Fombrun, Social Network Analysis for organizations, Academy of Management. 4, 4 (1979) 507-519.

[5] H. Breinlich, Trade liberalization and industrial restructuring through mergers and acquisitions, Journal of International Economics. 76,2 (2008) 254-266

[6] W. Huang, Z. Gao, X. Zhuang, Study based on complex network of Chinese listed companies' cross-regional M\&A, Journal of Industrial Technological Economics. 6 (2015) 128-136.

[7] J. Liu, Lectures on whole network approach: A practical guide to UCINET. Shanghai people's publishing house, Shang Hai, 2009.

[8] R. Hou, J. Yang, C. Yao, Global industrial restructuring and transfer: An analysis method based on complex networks for cross-border M\&A, Journal of Systems \& Management. 12 (2007) 13-169. 